\title{
THE BURDEN OF SLEEP DISORDERED BREATHING IN CHILDREN WITH SICKLE CELL DISEASE
}

\author{
Ilaria Liguoro ${ }^{1}$, Michele Arigliani ${ }^{2}$, Hui-leng Tan ${ }^{3}$, and Atul Gupta ${ }^{4}$ \\ ${ }^{1}$ University of Udine \\ ${ }^{2}$ Great Ormond Street Hospital for Children \\ ${ }^{3}$ Royal Brompton Hospital \\ ${ }^{4}$ King's College Hospital NHS Trust
}

July 8, 2021

\begin{abstract}
Children with sickle cell disease (SCD) have an increased risk of sleep disordered breathing (SDB) compared with the general pediatric population. There has been a growing research interest on this field in recent years, yet many questions regarding risk factors and clinical implications of SDB remain unclear. The aim of this review is to provide a concise narrative and systematic synthesis of the available evidence on the epidemiology, clinical presentation, complications and management, of SDB in children with SCD. An electronic search was conducted on studies published from the 1st of January 2000 to the 31 st of December 2020 in PubMed/Medline, Scopus and Cochrane databases. All studies focusing on SDB in children with SCD aged from 0 to 20 years were included. Studies were eligible for inclusion if available in the English language. A quantitative synthesis of the included studies was performed. Only studies focusing on specific treatment outcomes were included in a meta-analytic process. A total of 190 papers were initially identified. After screening the title and abstract, 112 articles were evaluated for eligibility. At the end of the selection process, 62 studies were included in the analysis. Sleep-disordered breathing is associated with worse neurological, neurocognitive and cardiological outcomes, whereas the association with frequency or severity of vaso-occlusive pain events and acute chest syndrome was not clarified. Therapeutic interventions like adenotonsillectomy or oxygen supply may result in a significant increase in mean nocturnal oxygen saturation but effective clinical implications remain still unclear.
\end{abstract}

\section{Hosted file}

main_manuscript_r.doc available at https://authorea.com/users/424584/articles/529649-theburden-of-sleep-disordered-breathing-in-children-with-sickle-cell-disease

\section{Hosted file}

Tables.docx available at https://authorea.com/users/424584/articles/529649-the-burden-ofsleep-disordered-breathing-in-children-with-sickle-cell-disease 


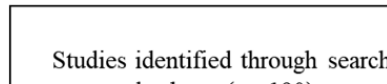
database $(n=190)$

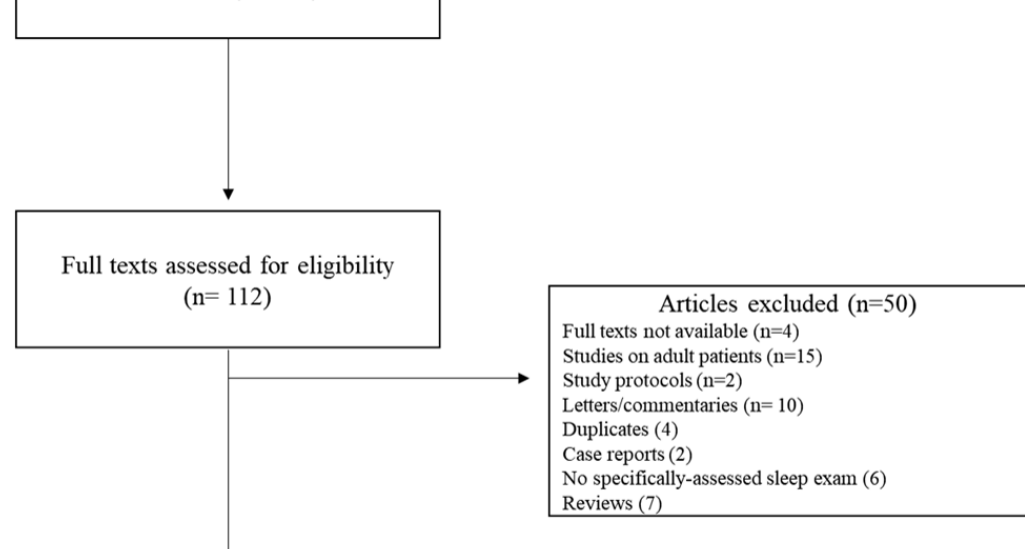

Studies included $(n=62)$
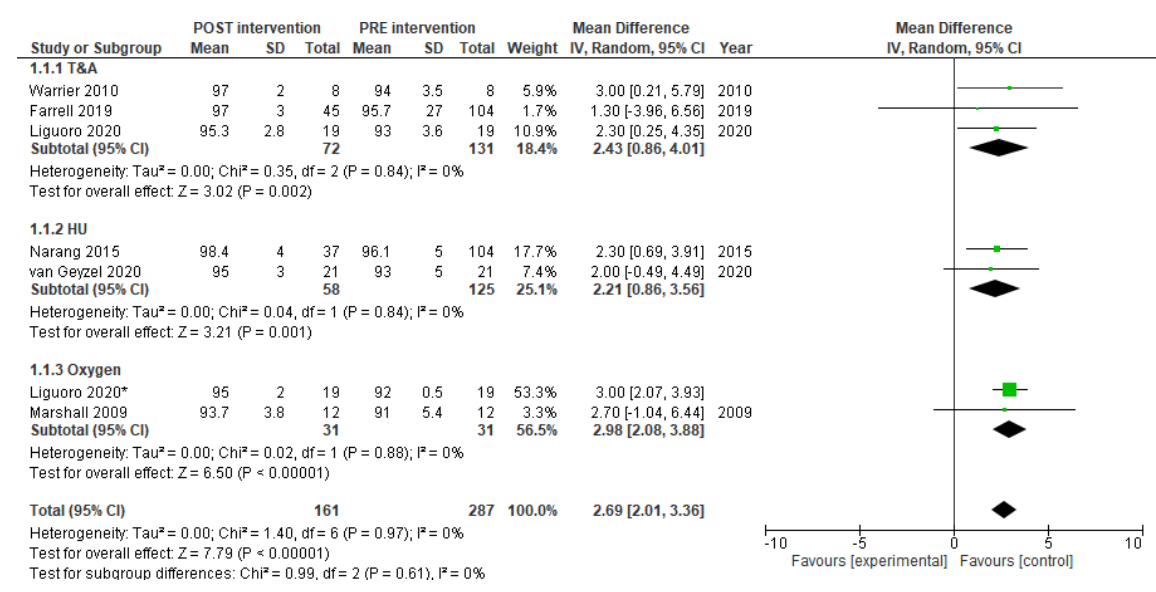

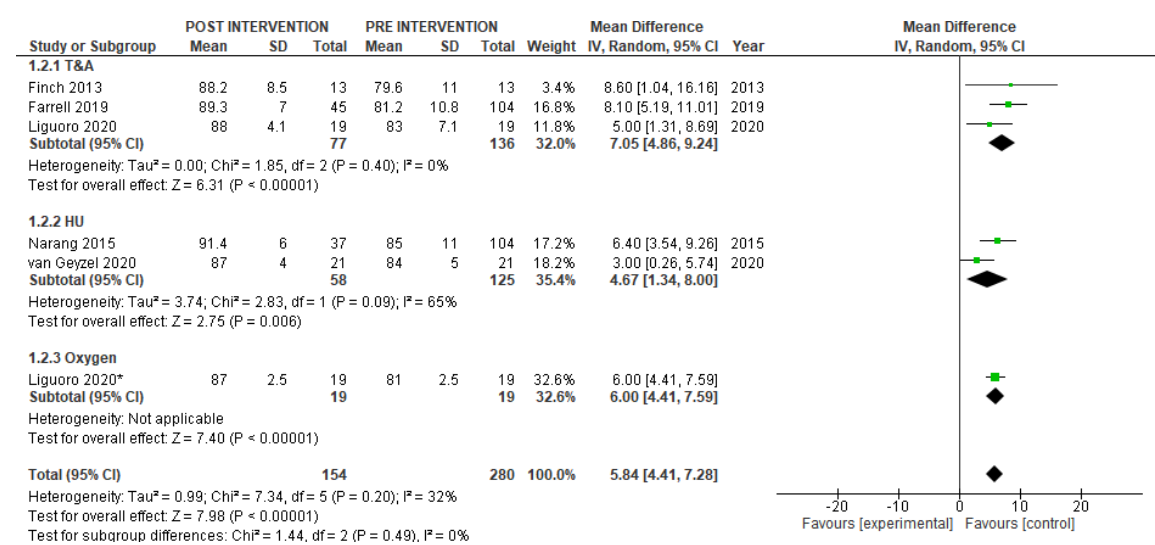




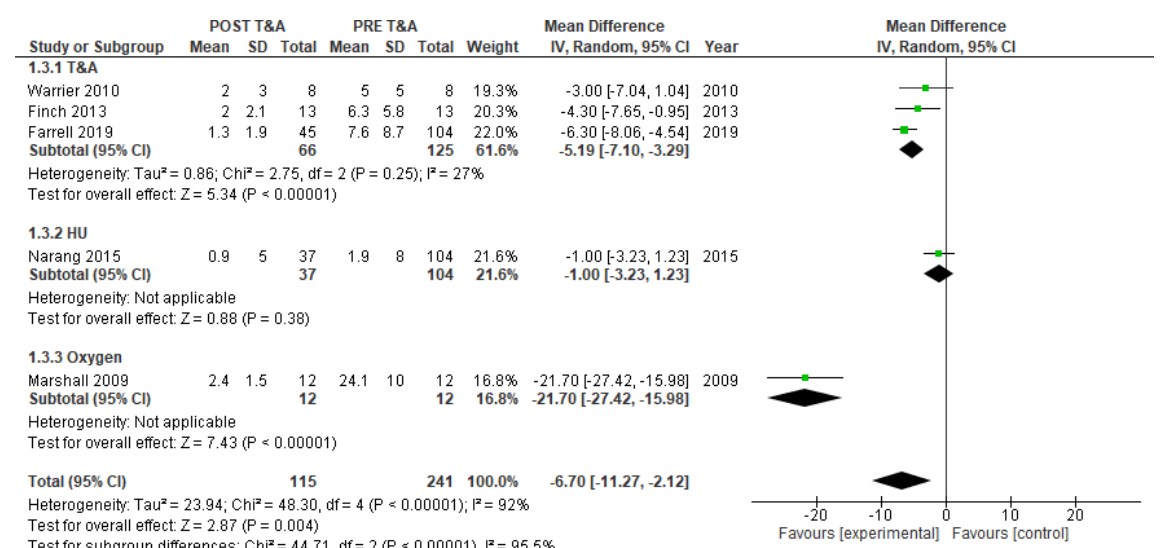

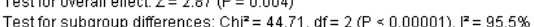

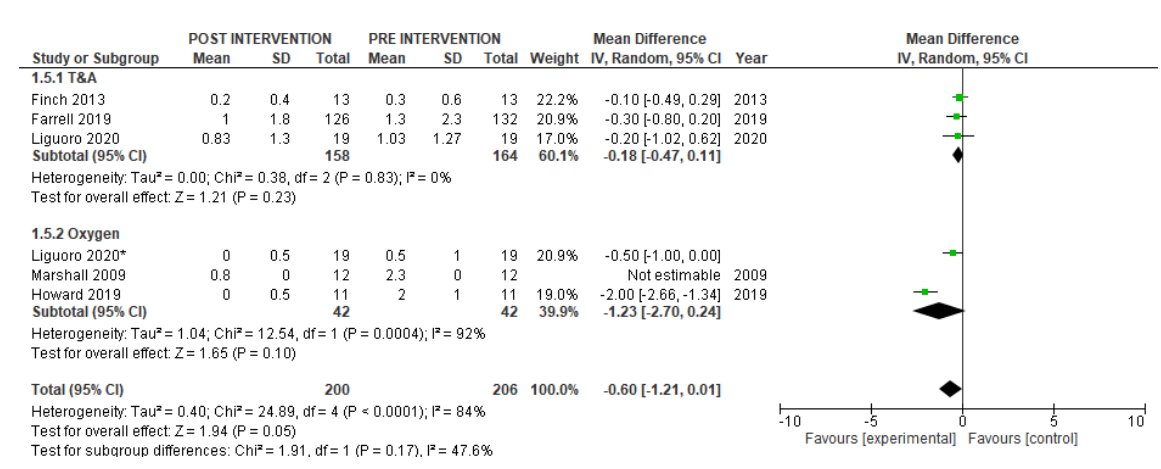

Test for subaroup differences: $\mathrm{Chi}^{2}=1.91, \mathrm{df}=1(\mathrm{P}=0.17), \mathrm{P}^{2}=47.6 \%$
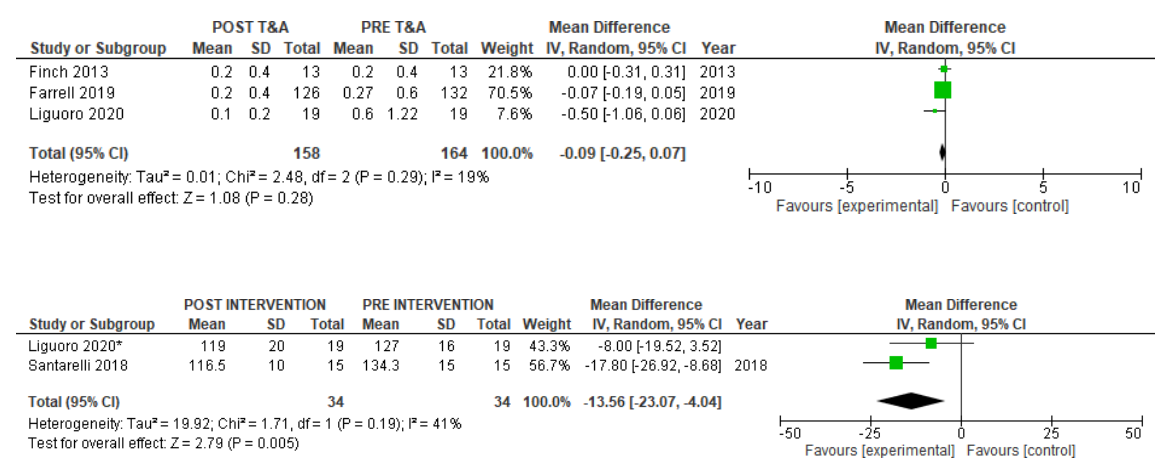